\title{
Skeletal Muscle Utilization of Free Fatty Acids in Women with Visceral Obesity
}

Sheri R. Colberg, Jean-Aimé Simoneau, F. Leland Thaete, and David E. Kelley

Department of Veterans Affairs Medical Center and Departments of Medicine and Radiology, University of Pittsburgh

School of Medicine, Pittsburgh, Pennsylvania 15261; and the Physical Activity Sciences Laboratory, Laval University, Ste-Foy, Québec

\begin{abstract}
Visceral obesity is strongly associated with insulin resistance. One potential cause is increased availability of FFA. Alternatively, it has been proposed that there is impaired oxidation of lipid in individuals at risk for obesity. The extent to which either concept involves skeletal muscle is uncertain. To examine these opposing hypotheses, 17 healthy lean and obese premenopausal women, among whom cross-sectional area of visceral fat ranged from 18 to $180 \mathrm{~cm}^{2}$, participated in leg balance studies for measurement of FFA and glucose utilization during basal and insulin-stimulated conditions. A metabolic profile of skeletal muscle, based on enzyme activity, was determined in vastus lateralis muscle obtained by percutaneous biopsy. Visceral fat content was negatively correlated with insulin sensitivity (rates of leg glucose uptake and storage), but insulin resistance was not caused by glucose-FFA competition. During hyperinsulinemia, neither leg FFA uptake nor oxidation was increased in women with visceral obesity. During fasting conditions, however, rates of FFA uptake across the leg were negatively correlated with visceral adiposity as were activities of muscle carnitine palmitoyl transferase and citrate synthase. In summary, visceral adiposity is clearly associated with skeletal muscle insulin resistance but this is not due to glucose-FFA substrate competition. Instead, women with visceral obesity have reduced postabsorptive FFA utilization by muscle. (J. Clin. Invest. 1995. 95:18461853.) Key words: visceral obesity $\bullet$ insulin resistance $\bullet$ human skeletal muscle $\bullet$ free fatty acid metabolism • carnitine palmitoyl transferase
\end{abstract}

\section{Introduction}

Nearly one third of adults in the United States are overweight (1). One phenotype of obesity, that characterized by increased visceral fat deposition, particularly increases risk for non-insulin-dependent diabetes mellitus, essential hypertension, and dyslipidemia (2-5). These associations have been attributed to insulin resistance. One potential cause of insulin resistance within skeletal muscle of individuals with visceral obesity is increased FFA utilization by muscle (6). The role of glucoseFFA substrate competition in evoking insulin resistance in obe-

Address correspondence to David E. Kelley, MD, E-1140 BioMedical Science Tower, University of Pittsburgh, Pittsburgh, PA 15261. Phone: 412-648-9770; FAX: 412-648-7047.

Received for publication 9 August 1994 and in revised form 16 November 1994.

The Journal of Clinical Investigation, Inc. Volume 95, April 1995, 1846-1853 sity has been supported by some, but not all, investigations of systemic glucose and FFA metabolism (7-9). However, to our knowledge there has not been an investigation which has examined in vivo muscle FFA uptake in individuals with visceral obesity during simultaneous measurement of muscle insulin sensitivity.

In contrast to the hypothesis that FFA causes insulin resistance, other investigations suggest instead that lipid oxidation is impaired in individuals at risk for obesity $(10,11)$. While the tissue(s) responsible for impaired fat oxidation has not been clearly identified, the recent finding that skeletal muscle lipoprotein lipase activity is decreased in association with increased systemic RQ (12), and is diminished in individuals with visceral obesity (13), suggests a defect of fat utilization by muscle. Among healthy, lean individuals there is efficient uptake and oxidation of plasma FFA in skeletal muscle during postabsorptive conditions $(14,15)$. Whether this pattern is diminished in individuals with visceral obesity has not been determined previously.

This study was undertaken to test these two alternative and opposing hypotheses regarding the effects of visceral obesity upon substrate utilization by muscle. The first hypothesis is that glucose-FFA substrate competition contributes to insulin resistance of skeletal muscle in women with visceral obesity. This was tested by measuring simultaneous rates of FFA and glucose uptake by muscle, using leg balance methods, during insulin-stimulated conditions in lean and obese healthy premenopausal women. The second hypothesis is that muscle FFA utilization is diminished in women with visceral obesity during fasting conditions. To test this hypothesis, rates of leg FFA uptake were measured during basal conditions and vastus lateralis muscle was obtained by percutaneous biopsy for analysis of enzyme activities which have potential regulatory roles for glucose and FFA metabolism. The findings support the latter hypothesis, of impaired FFA utilization in women with visceral obesity, and indicate that insulin resistance in such individuals is not due to substrate competition.

\section{Methods}

Subjects. The clinical characteristics of the 17 women who participated in this investigation are shown in Table I. Women were recruited to comprise a group of lean and obese individuals, and, among obese subjects, to have equal numbers of women with upper or lower body fat distribution. There was a 10 -fold difference in visceral fat content among these women. At screening, an oral glucose tolerance test and medical examination were performed, and a fasting lipid profile was obtained. Women with impaired glucose tolerance, hypertension, dyslipidemia, or irregular menstrual cycles were excluded. Glucose clamp studies were performed in the prefollicular phase of their menstrual cycles. The volunteers were sedentary; women who participated in strenuous exercise more than once weekly were excluded. The range of plasma triglyceride was $0.31-1.21 \mathrm{mM}$, and the range for HDL cholesterol was $0.93-1.21 \mathrm{mM}$, demonstrating the absence of dyslipidemia. 
Table I. Body Composition Characteristics

\begin{tabular}{|c|c|c|c|c|c|}
\hline $\begin{array}{l}\text { Visceral fat } \\
\text { content }\end{array}$ & Weight & BMI & Fat mass & $\begin{array}{l}\text { Thigh adipose } \\
\text { content }\end{array}$ & Age \\
\hline $\mathrm{cm}$ & $k g$ & $\mathrm{~kg} / \mathrm{m}^{2}$ & $k g$ & $\mathrm{~cm}^{2}$ & $y r$ \\
\hline 18.5 & 57.0 & 19.3 & 11.0 & 54 & 24 \\
\hline 33.4 & 55.5 & 20.1 & 14.5 & 120 & 22 \\
\hline 40.2 & 52.0 & 20.3 & 15.0 & 122 & 32 \\
\hline 42.0 & 55.0 & 20.4 & 10.3 & 125 & 39 \\
\hline 51.7 & 69.0 & 23.9 & 18.8 & 120 & 33 \\
\hline 53.9 & 83.0 & 31.6 & 30.4 & 222 & 32 \\
\hline 59.1 & 83.0 & 31.2 & 27.6 & 242 & 25 \\
\hline 60.4 & 58.5 & 24.7 & 12.8 & 173 & 38 \\
\hline 63.7 & 101.0 & 36.7 & 39.9 & 301 & 31 \\
\hline 74.2 & 81.0 & 30.1 & 33.3 & 183 & 33 \\
\hline 80.4 & 102.0 & 33.7 & 43.9 & 350 & 27 \\
\hline 101.7 & 80.5 & 28.5 & 26.5 & 202 & 26 \\
\hline 103.0 & 90.0 & 34.3 & 30.0 & 248 & 35 \\
\hline 106.3 & 113.5 & 38.8 & 39.4 & 339 & 30 \\
\hline 118.0 & 87.5 & 29.6 & 31.8 & 245 & 38 \\
\hline 160.9 & 80.5 & 29.6 & 30.9 & 218 & 34 \\
\hline 184.4 & 89.0 & 36.6 & 38.7 & 195 & 35 \\
\hline $79.5 \pm 10.5$ & $78.7 \pm 4.3$ & $26.8 \pm 2.6$ & $28.8 \pm 1.5$ & $203 \pm 19$ & $31.4 \pm 1.2$ \\
\hline
\end{tabular}

The range for systolic blood pressure was $102-130 \mathrm{mmHg}$, and for diastolic blood pressure the range was $66-88 \mathrm{mmHg}$, demonstrating that all subjects were normotensive. None of the women were taking medication on a regular basis, including use of oral contraceptives. The protocol was approved by the University of Pittsburgh Institutional Review Board, and informed consent was obtained from each subject.

Body composition. Standing height, weight, minimal waist circumference, and maximum hip circumference were measured using standard methods (16). Computed tomography ( 9800 scanner; General Electric, Milwaukee, WI) was used to measure intraabdominal adipose tissue using a $10-\mathrm{mm}$ cross-sectional scan through the abdomen centered on the disc space between the fourth and fifth lumbar vertebrae (17). At mid-thigh, a cross-sectional CT scan was obtained, and subcutaneous adipose area was measured electronically (18); for a separate protocol, muscle attenuation was also examined (19). Total body adiposity was estimated using a four-electrode bioelectrical impedance system (Bioelectric Sciences, Inc., La Jolla, CA) at the right wrist and ankle, as described previously (18).

Protocol. To determine leg FFA uptake and insulin sensitivity, subjects were admitted to the University of Pittsburgh General Clinical Research Center. On the morning of a study, subjects reported at approximately 6:00 a.m. after fasting overnight for at least $12 \mathrm{~h}$. Subjects were instructed to consume a balanced diet containing at least $200 \mathrm{~g}$ of carbohydrate daily, for $3 \mathrm{~d}$ before a study, and not to exercise on the day preceding a study. Subjects were placed at bed rest on admission. To measure rates of glucose utilization, a primed $(20 \mu \mathrm{Ci})$, continuous $\left(0.20 \mu \mathrm{Ci} / \mathrm{min}\right.$ ) infusion of [ $\left.3-{ }^{3} \mathrm{H}\right]$ glucose (New England Nuclear, Boston, MA) was started in an antecubital vein, with $2 \mathrm{~h}$ allowed for isotopic equilibration. To measure arterio-venous differences across the leg, catheters were placed in a radial artery and a femoral vein, as described previously (20). To measure leg uptake of FFA, a continuous $(0.3 \mu \mathrm{Ci} / \mathrm{min})$ infusion of $\left[9,10-{ }^{3} \mathrm{H}\right]$ oleate was started with $1 \mathrm{~h}$ allowed for isotopic equilibration. Measurement of postabsorptive metabolism was conducted for $45 \mathrm{~min}$. Arterial and femoral vein samples for glucose, FFA specific activity, lactate, alanine, and glycerol were obtained at 15-min intervals. Arterial samples for glucose specific activity and plasma insulin were obtained at these times. At 5-min intervals, arterial and femoral vein blood samples were obtained for measurement of blood $\mathrm{O}_{2}$ and plasma $\mathrm{CO}_{2}$ content, to determine leg gas exchange for indirect calorimetry measurements. Systemic indirect calorimetry was continuously performed during this baseline period using an open canopy system (Delta Trac, Anaheim, CA). Leg blood flow was determined in triplicate using mercury strain gauge plethysmography (Hokanson Inc., Bellevue, WA). After completing postabsorptive measurements, a percutaneous needle biopsy of the vastus lateralis muscle was performed using a Bergstrom needle with suction, as described previously (21), and muscle was immediately frozen in liquid nitrogen for later analysis of enzyme activity.

15 min after completion of the muscle biopsy, a 5-h euglycemic insulin infusion was started. For $3 \mathrm{~h}$, insulin was infused at $10 \mathrm{mU} / \mathrm{min} /$ $\mathrm{m}^{2}$, followed by a $2-\mathrm{h}$ insulin infusion at $40 \mathrm{mU} / \mathrm{min} / \mathrm{m}^{2}$, to measure the effects of mild and moderate hyperinsulinemia on leg glucose and FFA utilization. Euglycemia was maintained using the glucose clamp method (22), with a variable infusion of $20 \%$ dextrose, to which $\left[3-{ }^{3} \mathrm{H}\right]$ glucose $(0.16 \mu \mathrm{Ci} / \mathrm{g}$ dextrose $)$ had been added to maintain stable plasma glucose specific activity (23). During the final $30 \mathrm{~min}$ of each insulin infusion (i.e., $150-180 \mathrm{~min}, 270-300 \mathrm{~min}$ ), arterial and venous sampling was carried out as described for the postabsorptive period.

Analysis. Plasma glucose was measured using a glucose oxidase system (model 23A; Yellow Springs Instrument Co., Yellow Springs, $\mathrm{OH})$. Arterial and femoral venous blood $\mathrm{O}_{2}$ content was determined with a co-oximeter (IL282 co-oximeter system; Allied Instrument Laboratory, Lexington, MA). Plasma $\mathrm{CO}_{2}$ content was measured (system $1304 \mathrm{pH} /$ blood gas analyzer; Allied Instrument Laboratory), and each blood gas analysis immediately followed blood sampling. Plasma $\mathrm{CO}_{2}$ content was later adjusted to blood $\mathrm{CO}_{2}$ content using a regression equation (24), containing hemoglobin, saturation, and sample $\mathrm{pH}$. To measure oleate radioactivity, plasma FFA were extracted according to the method of Dole and Meinertz (25) using $5 \mathrm{ml}$ of extraction mixture. The procedure was modified according to Robin et al. (26) to include a heptane wash of the aqueous phase, and an internal standard of [1${ }^{14} \mathrm{C}$ ]palmitate was added to each sample to assess recovery. Dual channel liquid scintillation counting was performed to measure $\left[{ }^{3} \mathrm{H}\right]$ oleate and $\left[{ }^{14} \mathrm{C}\right]$ palmitate. In preliminary studies, minimal cross-over of $\left[{ }^{3} \mathrm{H}\right]-$ glucose from the aqueous phase of plasma into the organic extract was found; recovery of $\left[3-{ }^{3} \mathrm{H}\right.$ ] glucose was $0.2 \pm 0.1 \%$. At the level of plasma glucose radioactivity attained in the current study $(\sim 2,000 \mathrm{dpm} / \mathrm{ml})$, cross-over into organic extracts would have added $\sim 5-10 \mathrm{dpm}$ per sample, a minor effect further negated since measurement of arteriovenous differences in FFA radioactivity was the main objective. Plasma $\left[3{ }^{3} \mathrm{H}\right]$ glucose radioactivity was determined after deproteinization of plasma using barium hydroxide and zinc sulfate with evaporation of the aqueous extract $(\mathrm{pH}=7.3$ ) to dryness to remove tritiated water before liquid scintillation counting, as previously described (27). Recovery of plasma glucose radioactivity was $84 \pm 1.0 \%$. Preliminary studies demonstrated negligible recovery of $\left[9,10-{ }^{3} \mathrm{H}\right]$ oleate $(0.02 \pm 0.01 \%)$, within the aqueous extract of plasma obtained by deproteinization of plasma using the barium/zinc procedure. Plasma FFA was measured using a commercially available enzymatic spectrophotometric assay (NEFA-C; Wako Chemical Inc., Dallas, TX). Plasma glycerol was assayed by an enzymatic method (Triglyceride GPO-Trinder kit; Sigma Chemical Co., St. Louis, MO). Lactate and alanine were determined by enzymatic assays, and plasma insulin was determined by radioimmunoassay, as previously described (18).

Muscle analyses. Adequate muscle samples were obtained at biopsy from 15 of the 17 subjects. Muscle samples were immediately frozen in liquid nitrogen and stored at $-70^{\circ} \mathrm{C}$ until shipment in dry ice to the Physical Activity Sciences Laboratory at Laval University, for analysis by one of the investigators (J.-A. Simoneau), who was blinded as to the clinical status of each subject. One of the shipments, containing samples from 3 volunteers, was destroyed because of thawing during shipment, so muscle from only 12 subjects was available for analysis. The activity levels of creatine kinase (EC 2.7.3.2), phosphofructokinase 


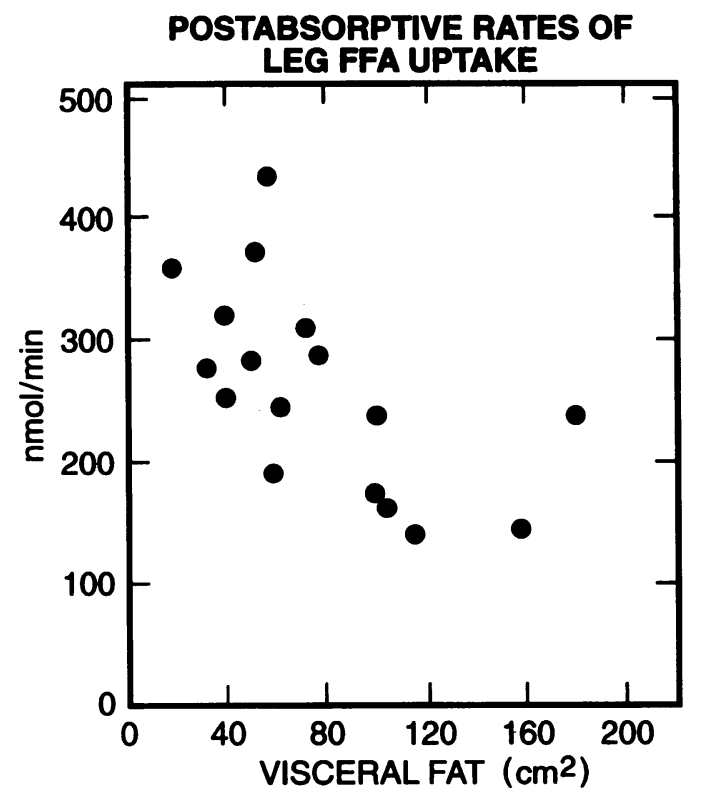

Figure 1. Rates of leg FFA uptake during postabsorptive conditions are plotted against respective values for visceral fat content.

(EC 2.7.1.11), citrate synthase (CS, EC 4.1.3.7), ${ }^{1}$ cytochrome $c$ oxidase (EC 1.9.3.1), and 3-hydroxyacyl CoA dehydrogenase (HADH, EC 1.1.1.35) were spectrophotometrically determined at $30^{\circ} \mathrm{C}$ according to previously established techniques from this laboratory (28). For analysis of muscle carnitine palmitoyl transferase (CPT, EC 2.3.1.21), 7.5 $\mathrm{mg}$ of tissue was added to $0.1 \mathrm{M}$ phosphate buffer and $2 \mathrm{mM}$ EDTA, $\mathrm{pH} 7.2$ (dilution of $1: 40 \mathrm{wt} / \mathrm{vol}$ ), in a ground-glass homogenizer (1.5 $\mathrm{ml}$ ) and homogenate prepared in an ice bath. Homogenate was transferred into $1.5-\mathrm{ml}$ polypropylene tubes and sonicated 6 times at $20 \mathrm{~W}$, on ice, with each sonication lasting $5 \mathrm{~s}$ and interrupted by $85 \mathrm{~s}$. The assay for CPT activity was performed immediately to avoid degradation of the enzyme. Carnitine palmitoyl-CoA transferase was assayed spectrophotometrically at $25^{\circ} \mathrm{C}$ in the forward direction by following the appearance of CoASH using the general DTNB (5,5'-dithiobis(2-nitrobenzoic acid); Ellmans reagent). Free CoASH reacts irreversibly with DTNB to form a mixed disulfide + 5-thiol-2-nitrobenzoate which has a molar extinction coefficient of $13,600 \mathrm{~cm}^{-1}$ at $412 \mathrm{~nm}$ (29). Muscle glycogen phosphorylase was determined at $25^{\circ} \mathrm{C}$ as described by Bass et al. (30). Values of enzyme activities were expressed in units per gram or milliunits per gram of wet weight muscle.

Calculations. Leg net balance of glucose, lactate, alanine, glycerol, $\mathrm{O}_{2}$, and $\mathrm{CO}_{2}$ were calculated as the product of arterio-venous differences and leg blood flow. Fractional extraction of FFA by the leg was calculated as arterio-venous differences of FFA radioactivity divided by arterial FFA radioactivity (31). Leg FFA uptake was calculated as the product of FFA fractional extraction, arterial FFA concentration, and leg plasma flow. Leg FFA release was calculated as the difference between the leg FFA uptake and net balance of FFA across the leg. Systemic glucose appearance and utilization were calculated using nonsteady state equations adjusted for the infusion of labeled dextrose (23). Systemic rates of carbohydrate and lipid oxidation were calculated from values for gas exchange and urine urea nitrogen excretion using the equations of Frayn (32), and these equations were adapted for indirect calorimetry across a limb, as previously described (20), using empiric

1. Abbreviations used in this paper: $\mathrm{BMI}$, body mass index; CPT, carnitine palmitoyl transferase; CS, citrate synthase; FFM, fat free mass; HADH, 3-hydroxyacyl CoA dehydrogenase.
Table II. Skeletal Muscle Enzyme Activity

\begin{tabular}{lcccc}
\hline & & & \multicolumn{2}{c}{ Range } \\
\cline { 3 - 5 } & Mean & SD & Minimum & Maximum \\
\hline Creatine kinase & 415 & 90 & 331 & 589 \\
Phosphofructokinase & 58 & 13 & 36 & 75 \\
CS & 9.9 & 2.1 & 7.1 & 14.2 \\
HADH & 15.7 & 2.1 & 12.6 & 19.2 \\
CPT & 0.11 & 0.02 & 0.07 & 0.14 \\
$\begin{array}{l}\text { Cytochrome } c \\
\quad \text { oxidase }\end{array}$ & 6.3 & 1.4 & 3.6 & 8.0 \\
$\begin{array}{l}\text { Glycogen } \\
\text { phosphorylase }\end{array}$ & 18.8 & 3.9 & 11.6 & 25.3 \\
\hline
\end{tabular}

Enzyme activity is units per gram of wet weight except for CPT which is milliunits per gram of wet weight.

constants for muscle protein oxidation during basal and insulin-stimulated conditions (33). Leg glucose storage was calculated as the difference between leg glucose uptake and the sum of leg glucose oxidation and net balance of lactate and alanine; with negative values representing net glycogenolysis. Systemic nonoxidative glucose metabolism was calculated as the difference between glucose utilization and glucose oxidation.

Statistics. Data are expressed as means \pm SEM. Multiple linear regression was used to determine the significance of potential associations between visceral fat content and other metabolic parameters (RS1; BBN Software Inc., Cambridge, MA). Repeated measures analysis of variance was used to compare postabsorptive and insulin-stimulated conditions.

\section{Results}

Postabsorptive metabolism. During postabsorptive conditions, FFA uptake across the leg was negatively correlated with visceral fat content $(r=-0.60, P=0.01)$, as shown in Fig. 1 . Fasting rates of FFA uptake across the leg were not correlated with systemic fat mass, body mass index (BMI), or subcutaneous fat of either abdomen or thigh. Metabolic profiles of skeletal muscle, based on activities of seven enzymes, are shown in Table II. A strong negative correlation was found between activity of muscle CPT and visceral fat content $(r=-0.76, P$ $<0.05$ ), and CPT activity was positively correlated with postabsorptive rates of FFA uptake by muscle $(r=0.52, P<0.05)$, as shown in Fig. 2. Glucose uptake across the leg during basal conditions was $100 \pm 40 \mathrm{nmol} / \mathrm{min}$, and there was net release of lactate and alanine at $80 \pm 60 \mathrm{nmol} / \mathrm{min}$ (expressed in glucose equivalents). The basal rate of muscle glycogenolysis was $250 \pm 80 \mathrm{nmol} / \mathrm{min}$. These parameters of leg glucose metabolism were not correlated with visceral obesity.

Plasma FFA concentration during basal conditions was $496 \pm 36 \mu \mathrm{M}$, with a systemic rate of appearance for FFA of $7.13 \pm 0.57 \mu \mathrm{mol} / \mathrm{min} / \mathrm{kg}$ fat free mass (FFM) and for oxidation of FFA of $4.64 \pm 0.22 \mu \mathrm{mol} / \mathrm{min} / \mathrm{kg}$ FFM. These parameters did not correlate significantly with visceral fat content. During postabsorptive conditions, the release of FFA across the leg was $432 \pm 34 \mathrm{nmol} / \mathrm{min}$, with a net release of glycerol across the leg at $241 \pm 34 \mathrm{nmol} / \mathrm{min}$, reflecting a ratio of FFA to glycerol release across the leg of $2.3 \pm 0.3$.

Oxidative metabolism by leg tissue was assessed by limb 

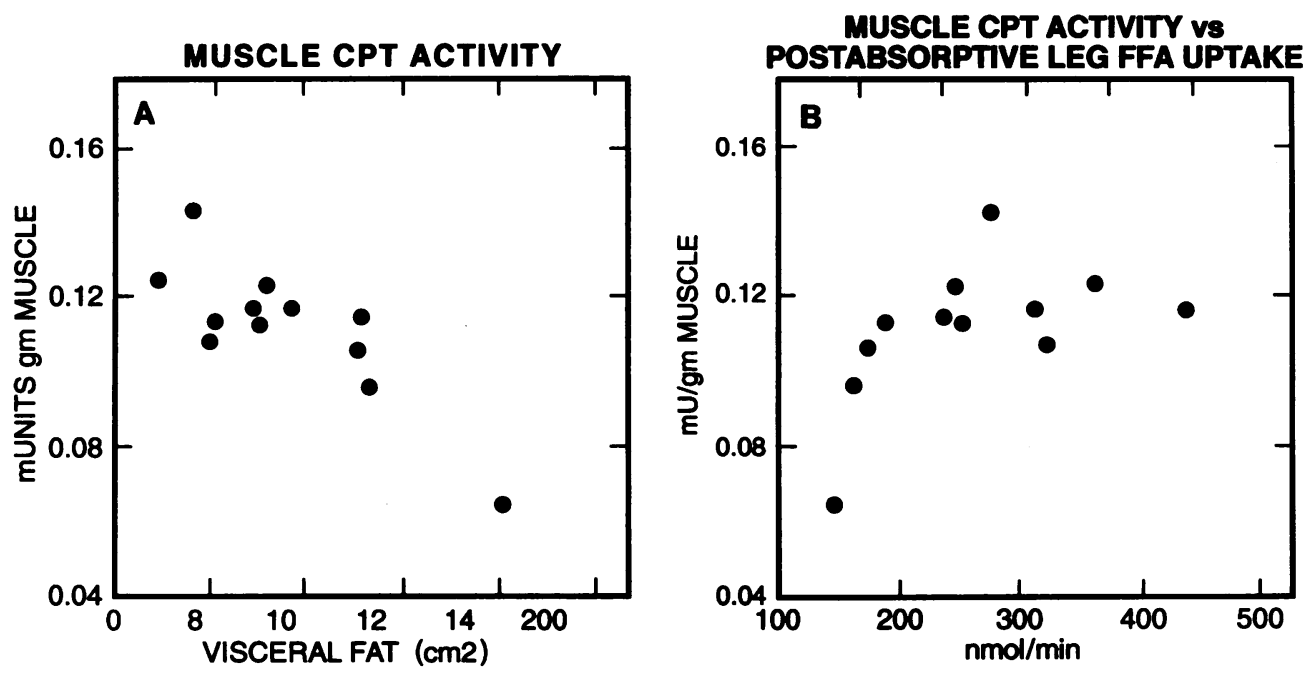

Figure 2. A shows the relationship between activity of muscle CPT and visceral fat content. $B$ shows the relationship between activity of muscle CPT and rates of leg FFA uptake during postabsorptive conditions. indirect calorimetry. The basal RQ across leg tissue was $0.80 \pm 0.02$, with rates of glucose and lipid oxidation of $270 \pm 70$ and $138 \pm 21 \mathrm{nmol} / \mathrm{min}$, respectively. Visceral obesity had a negative though nonsignificant correlation with rates of lipid oxidation across the leg during basal conditions $(r=-0.36, P$ $=0.16$ ). As shown in Fig. 3, CS activity in skeletal muscle, a marker enzyme of mitochondrial content, was positively correlated with lipid oxidation across the leg during fasting conditions ( $r=0.48, P=0.06$ ), and CS activity was negatively correlated with visceral obesity $(r=-0.51, P<0.05)$. Fasting rates of leg glucose oxidation were correlated with activity of muscle glycogen phosphorylase $(r=0.66, P<0.05)$. Activity of other enzymes, including activities of HADH (a marker enzyme of mitochondrial fatty acid $\beta$-oxidation ) and CPT, was not significantly correlated with basal rates of leg lipid oxidation.

Mild hyperinsulinemia. $3 \mathrm{~h}$ of insulin infusion at $10 \mathrm{mU} /$ $\mathrm{m}^{2} / \mathrm{min}$ increased arterial insulin to a steady state level of $168 \pm 21 \mathrm{pM}(P<0.01)$. FFA uptake across the leg decreased from a fasting rate of $261 \pm 20$ to $115 \pm 12 \mathrm{nmol} / \mathrm{min}(P<0.01)$, with significant suppression of FFA release by the leg $(144 \pm 28$ $\mathrm{nmol} / \mathrm{min})$, as well as glycerol release $(111 \pm 34 \mathrm{nmol} / \mathrm{min})$.
Glucose uptake across the leg increased during mild hyperinsulinemia to $420 \pm 110 \mathrm{nmol} / \mathrm{min}(P<0.01)$, while rates for net release of lactate and alanine were unaffected $(80 \pm 50 \mathrm{nmol} /$ $\mathrm{min})$. Leg RQ did not change significantly during mild hyperinsulinemia $(0.82 \pm 0.03)$, nor did rates of glucose oxidation $(330 \pm 70 \mathrm{nmol} / \mathrm{min})$ and rates of lipid oxidation across the leg $(170 \pm 35 \mathrm{nmol} / \mathrm{min})$. Compared with basal conditions, mild hyperinsulinemia suppressed muscle glycogenolysis (14 \pm 89 $\mathrm{nmol} / \mathrm{min}, P<0.05$ ) as the increase in uptake of plasma glucose accounted for glucose oxidation and net release of lactate and alanine.

Systemically, mild hyperinsulinemia suppressed arterial FFA concentration $(136 \pm 19 \mu \mathrm{M})$, systemic rate of appearance of FFA $(2.68 \pm 0.28 \mu \mathrm{mol} / \mathrm{min} / \mathrm{kg}$ FFM $)$, and systemic lipid oxidation $(3.23 \pm 0.25 \mu \mathrm{mol} / \mathrm{min} / \mathrm{kg} \mathrm{FFM})($ all $P<0.01)$. Hepatic glucose production decreased from a fasting rate of $15.4 \pm 1.0$ to $4.0 \pm 0.8 \mu \mathrm{mol} / \mathrm{min} / \mathrm{kg}$ FFM during mild hyperinsulinemia $(P<0.01)$, while systemic glucose utilization increased to $21.5 \pm 1.2 \mu \mathrm{mol} / \mathrm{min} / \mathrm{kg}$ FFM $(P<0.01)$. The increase in glucose utilization was accounted for by an increase in systemic glucose oxidation, from a basal rate of $9.0 \pm 1.0$
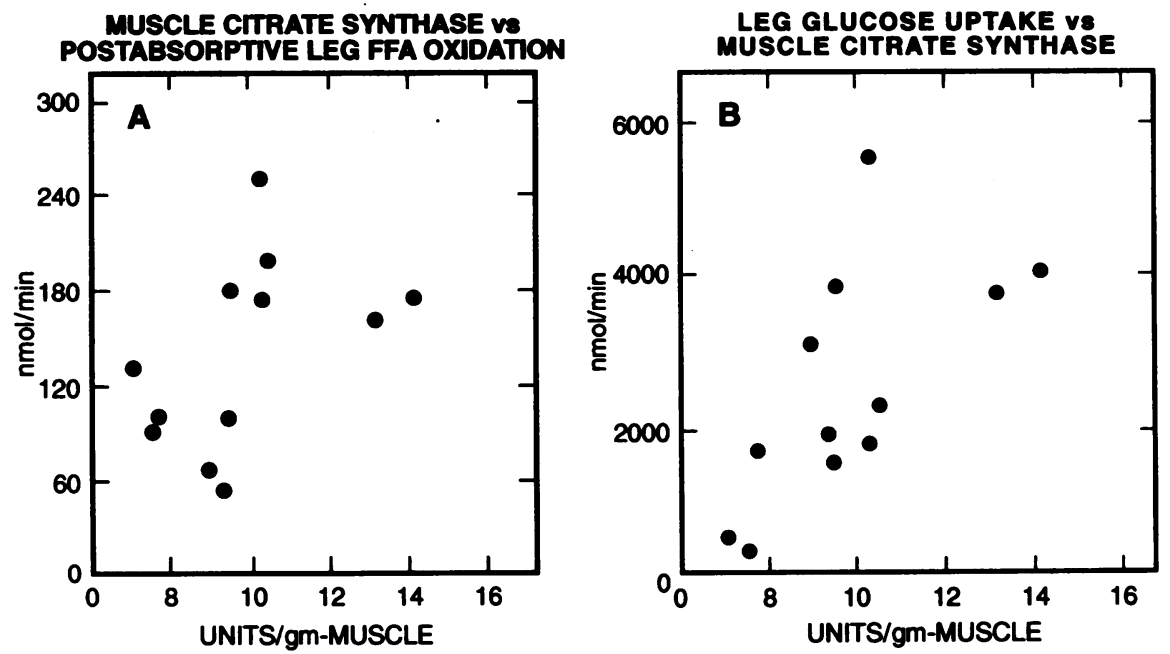

Figure 3. A shows the relationship between leg FFA uptake during postabsorptive conditions and muscle CS activity. $B$ shows the relationship between leg glucose uptake during moderate hyperinsulinemia and muscle CS activity. 


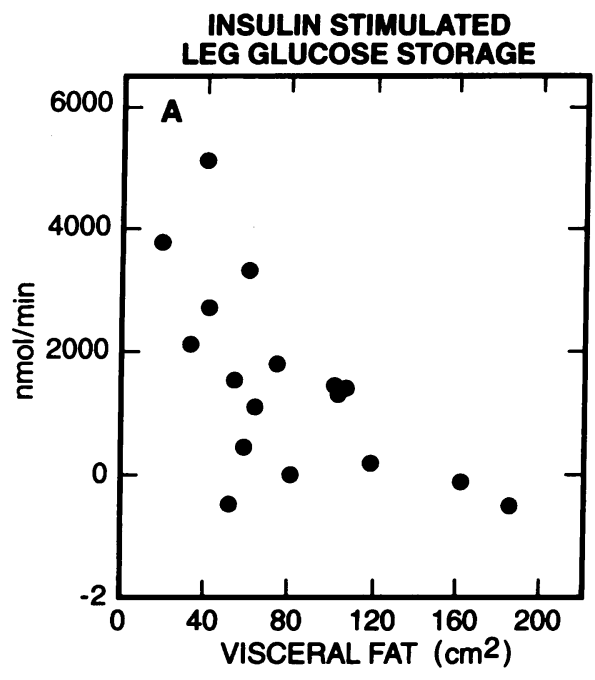

to $13.4 \pm 1.1 \mu \mathrm{mol} / \mathrm{min} / \mathrm{kg}$ FFM $(P<0.01)$, while systemic nonoxidative glucose metabolism did not change.

There were no significant correlations found between visceral obesity and rates of FFA or glucose uptake across the leg during mild hyperinsulinemia, and rates of FFA uptake across the leg were not correlated with corresponding rates of leg glucose uptake. Visceral fat had a negative, though nonsignificant, correlation with rates of lipid oxidation across the leg during mild hyperinsulinemia $(r=-0.42, P=0.10)$. Suppression of systemic FFA flux during mild hyperinsulinemia tended to be less in women with visceral obesity, but this correlation did not achieve significance $(r=-0.40, P=0.10)$. Women with increased visceral fat content also had a lesser decrease in rates of leg FFA uptake as compared with basal conditions ( $r$ $=-0.58, P<0.05)$.

Moderate hyperinsulinemia. During the subsequent 2-h insulin infusion at $40 \mathrm{mU} / \mathrm{min} / \mathrm{m}^{2}$, steady state arterial insulin concentration was $504 \pm 28$ pM. FFA uptake across the leg during moderate hyperinsulinemia was $110 \pm 13 \mathrm{nmol} / \mathrm{min}$, which was unchanged compared with mild hyperinsulinemia but less than during basal conditions $(P<0.01)$. Similarly, release of FFA across the leg $(107 \pm 14 \mathrm{nmol} / \mathrm{min})$ and of glycerol $(117 \pm 40 \mathrm{nmol} / \mathrm{min})$ were unchanged as compared with rates during mild hyperinsulinemia, but reduced compared with basal conditions $(P<0.01)$. Glucose uptake across the leg increased to $2,290 \pm 340 \mathrm{nmol} / \mathrm{min}(P<0.01)$ and was positively correlated $(r=0.68, P<0.01)$ with rates of systemic glucose utilization $(47.5 \pm 3.8 \mu \mathrm{mol} / \mathrm{min} / \mathrm{kg}$ FFM $)$. Net release of lactate and alanine across the leg did not change significantly $(120 \pm 10 \mathrm{nmol} / \mathrm{min})$. Leg RQ during moderate hyperinsulinemia did increase, to $0.90 \pm 0.03(P<0.05)$, with a significant decrease of lipid oxidation across the leg $(108 \pm 27 \mathrm{nmol} / \mathrm{min})$ and increased glucose oxidation $(640 \pm 100 \mathrm{nmol} / \mathrm{min}, P<$ $0.05)$. Rates of glucose storage across the leg increased significantly compared with mild hyperinsulinemia, from $14 \pm 89$ to $1,540 \pm 320 \mathrm{nmol} / \mathrm{min}(P<0.01)$.

Rates of leg glucose storage during moderate hyperinsulinemia were negatively correlated with visceral obesity as shown in Fig. 4. A similar negative relationship was found between systemic nonoxidative glucose utilization $(25.6 \pm 3.3 \mu \mathrm{mol} / \mathrm{min} /$ $\mathrm{kg}$ FFM) and visceral fat content $(r=-0.59, P<0.01)$, without additional significance if other measures of obesity are added to the multiple regression model. There was relatively little variation in FFA uptake during moderate hyperinsulinemia with respect to visceral fat content, and no correlation was found between rates of FFA uptake across the leg during moderate hyperinsulinemia and simultaneous rates of leg glucose storage, as shown in Fig. 4. Also, neither leg glucose storage nor uptake had a significant correlation with lipid oxidation by leg tissue during moderate hyperinsulinemia (both $P>0.2$ ).

Other indices of obesity also had significant simple correlations with leg glucose storage and with systemic nonoxidative glucose utilization. However, in a multiple regression model containing five markers of obesity (visceral fat content, systemic fat mass, BMI, and subcutaneous areas of both thigh and abdominal fat), visceral obesity was the most powerful predictor of insulin resistance (i.e., rates of insulin-stimulated leg glucose storage), and each of the other measures did not retain independent significance. If other measures of adiposity are initially forced into the regression model, visceral obesity still retained independent significance.

There were two other metabolic markers found for insulin sensitivity of skeletal muscle. Insulin-stimulated glucose storage by muscle was increased in women with higher rates of postabsorptive lipid oxidation across the leg $(r=0.61, P<0.05)$. Using a multiple regression model, increased visceral fat $(r$ $=-0.63, P<0.01)$ and reduced basal leg FFA oxidation $(r$ $=0.61, P<0.01$ ) each contributed significantly in predicting insulin resistance $\left(r^{2}=0.56, P<0.01\right)$. The other marker of insulin sensitivity was activity of muscle CS, which had a positive correlation with leg glucose uptake during moderate hyperinsulinemia $(r=0.66, P<0.05)$.

During moderate hyperinsulinemia, arterial FFA concentration decreased to $94 \pm 12 \mu \mathrm{M}$, systemic FFA rate of appearance decreased to $2.18 \pm 0.23 \mu \mathrm{mol} / \mathrm{min} / \mathrm{kg}$ FFM, and systemic lipid oxidation also decreased (to $1.70 \pm 0.26 \mu \mathrm{mol} / \mathrm{min} / \mathrm{kg}$ FFM), each $P<0.01$. Systemic glucose oxidation increased to $21.9 \pm 1.3 \mu \mathrm{mol} / \mathrm{min} / \mathrm{kg}$ FFM. None of these systemic parameters were correlated with visceral fat content.

\section{Discussion}

One of the metabolic complications of visceral obesity is insulin resistance. The mechanism which accounts for the association 
between intraabdominal fat accumulation and insulin resistance in peripheral tissue, especially in skeletal muscle, is uncertain. Obese women with upper body fat distribution have been found to have increased flux of FFA $(7,34)$, and it has been suggested that insulin resistance of skeletal muscle could derive in part from glucose-FFA substrate competition (6). The current study was undertaken to examine the relationship between visceral fat content in healthy premenopausal women and corresponding patterns of FFA and glucose utilization by skeletal muscle. Among the volunteers in the current study, visceral fat was a clear marker of skeletal muscle insulin resistance as there was a strong negative correlation between visceral fat and rates of insulin-stimulated glucose storage in muscle. However, the findings do not support the hypothesis that the insulin resistance of visceral obesity is caused by glucose-FFA substrate competition. Rates of FFA uptake and oxidation across the leg during both mild and moderate hyperinsulinemia were not significantly affected by variability of visceral fat, nor were rates of insulinstimulated leg glucose uptake correlated with simultaneous rates of leg FFA uptake or oxidation.

During insulin-stimulated conditions, the tissues of the leg which are responsible for FFA uptake could be both muscle and adipose tissue. The leg balance method with sampling from the femoral vein, as used in this study, is not able to discriminate between FFA uptake by muscle versus adipose tissue. It is therefore possible that rates of muscle FFA uptake might have differed among women of varying visceral fat content, though leg FFA uptake per se did not. However, insulin-stimulated values for leg RQ estimated using limb indirect calorimetry were also unaffected by visceral obesity. Since it is generally thought that insulin resistance caused by glucose-FFA substrate competition occurs secondary to lipid oxidation, the data from limb indirect calorimetry also fail to support a prominent role for increased use of FFA as a cause of insulin resistance associated with visceral obesity. Recent studies (35), including one from our laboratory (31), indicate that FFA can impair insulin stimulation of muscle glycogen synthase. However, this mechanism of FFA-induced insulin resistance is contingent upon increased muscle uptake of FFA.

In this study, however, there was a significant relationship found between visceral fat content and muscle FFA utilization during basal conditions. Women with increased visceral fat content were found to have decreased uptake of FFA across the leg during postabsorptive conditions. Since there is net lipolysis during fasting conditions, rates of FFA uptake across the leg are chiefly due to uptake by muscle $(14,15)$. Neither fasting arterial FFA nor systemic FFA appearance were diminished in women with increased visceral fat, so the finding of decreased leg FFA uptake in these women suggests that muscle itself may have an important role in regulating the rate of FFA uptake. This concept is supported by the concurrent finding that activity of muscle CPT was correlated with fasting rates of leg FFA uptake, and CPT activity was negatively correlated with visceral fat content. The CPT mitochondrial complex has a rate-limiting role in the transfer of long chain acyl CoA esters into the mitochondria (36), and deficiency of this enzyme has been found to dramatically impair FFA utilization (37). Therefore, in the current study both the rates of FFA uptake across the leg and the activity of muscle CPT indicate that women with visceral obesity have a diminished capacity for FFA utilization by skeletal muscle during fasting conditions.
Within the past several years, several investigations indicate that skeletal muscle of obese individuals may have diminished capacity for lipid utilization. Zurlo and colleagues (10) found that an increased systemic RQ measured over $24 \mathrm{~h}$ within an indirect calorimetry chamber predicted subsequent weight gain independent of metabolic rate. Also from this group of investigators, Ferraro et al. found that activity of skeletal muscle lipoprotein lipase was negatively correlated with 24-h RQ (12), which suggests strongly that muscle is an important tissue contributing to impaired lipid oxidation. A negative correlation between waist to hip ratio and muscle lipoprotein lipase activity has been reported (12). In classic studies, Zierler and colleagues $(14,15)$ demonstrated that lipid oxidation normally predominates in skeletal muscle during postabsorptive conditions in association with high rates of FFA uptake across the limb. These findings were reconfirmed in the current study among lean healthy women. However, the current study indicates that FFA utilization by muscle during postabsorptive conditions is perturbed among women with increased visceral fat content. Additionally, visceral fat and insulin resistance were linked to enhanced glycolytic and reduced oxidative enzyme activities in muscle (19).

This study further suggests that a heightened capacity for muscle FFA utilization during fasting conditions is linked to insulin sensitivity. A positive relationship was found between fasting rates of FFA oxidation across the leg and rates of insulinstimulated glucose storage by muscle. Women with increased muscle CS activity had higher postabsorptive rates of muscle FFA utilization as well as increased insulin-stimulated muscle glucose storage. In contrast, women with visceral obesity had reduced fasting uptake of FFA by muscle, skeletal muscle insulin resistance, and lower activity of CS in muscle. This enzyme catalyzes formation of citrate from acetyl $\mathrm{CoA}$, the latter representing the biochemical convergence of FFA and glucose metabolism within the mitochondria (36). CS is a key enzymatic marker of muscle mitochondrial content and of overall aerobicoxidative potential of muscle (38). The finding that both fasting FFA metabolism and insulin-stimulated glucose metabolism are correlated with activity of CS suggests that regulation of postabsorptive use of FFA by muscle is integrally linked to phenotypic expression of insulin sensitivity. This concept has been suggested previously by the positive relationship between fasting activity of muscle lipoprotein lipase and insulin sensitivity (39), and more broadly by the findings that exercise, which potently enhances insulin sensitivity of muscle, concomitantly increases the capacity of muscle for lipid utilization (40).

Visceral obesity is one component of a syndrome which includes glucose intolerance, essential hypertension, and dyslipidemia, with the common linkage thought to be insulin resistance (2-5). Therefore, the question arises as to what extent do abnormalities of FFA utilization by muscle arise secondarily to glucose intolerance, dyslipidemia, or hypertension. Several recent studies from our laboratory indicate that hyperglycemia impairs muscle FFA utilization, and more specifically lipid oxidation, during fasting conditions $(41,42)$. The current study indicates, however, that the abnormality of muscle FFA utilization associated with visceral obesity is not solely occurring secondarily to other components of the insulin resistance syndrome. The premenopausal women participating in this study were carefully screened to exclude individuals with hypertension, glucose intolerance, or dyslipidemia. 
Whether visceral obesity develops as a consequence of impaired lipid utilization by muscle, or vice versa, is not resolved by the correlative relationships revealed in the current study, and this issue will require further research. Among the adverse effects to which impaired FFA utilization by muscle could contribute is potential diversion of FFA toward increased synthesis of triglyceride, either for lipoprotein synthesis in the liver or for fat storage in other tissues (5). Campbell et al. (43) have found that reesterification of FFA is increased in obesity. Impaired capacity for lipid oxidation by muscle could favor partitioning FFA toward triglyceride deposition within muscle itself, and triglyceride content of muscle is a powerful marker of insulin resistance (44).

In this study, among several measures of adiposity, visceral fat content as determined by computed tomography emerged as the strongest correlate with insulin resistance and other parameters of muscle metabolism. This is generally consistent with previous findings (45), but more information is needed to assess whether it is relative fat distribution, absolute amounts of visceral fat, or general corpulence which is of greatest importance for impaired muscle FFA and glucose metabolism. In a series of elegant studies, Jensen and colleagues have found that obese women with increased waist to hip ratio have insulin resistance in regulation of lipolysis $(7,34)$. We did not find a significant effect of visceral obesity on insulin regulation of lipolysis but it is likely that the differences between our results and those of Martin and Jensen (34) may be that the level of mild hyperinsulinemia in the current study was twofold higher than that studied by Martin and Jensen. Because of pronounced effects of insulin upon lipolysis (46), the higher insulin levels in the current study may have obscured potential differences among our subjects. However, with regard to the effects of mild hyperinsulinemia on muscle glucose metabolism, the primary effect which was found was suppression of glycogenolysis, and this is consistent with recent studies by Rossetti and $\mathrm{Hu}$ (47).

In summary, this study reconfirms the strong link between visceral obesity and skeletal muscle insulin resistance. The data on rates of FFA uptake across the leg during insulin infusion fail to support the hypothesis that glucose-FFA substrate competition is a cause of insulin resistance in visceral obesity. However, there were important new findings regarding rates of FFA uptake by muscle during fasting conditions, which in conjunction with determinations of muscle CPT and CS activities, indicate that the presence of visceral obesity is associated with diminished capacity for postabsorptive utilization of plasma FFA by skeletal muscle.

\section{References}

1. Williamson, D. F. 1993. Descriptive epidemiology of body weight and weight change in U.S. adults. Ann. Intern. Med. 119:646-649.

2. Bjorntorp, P. 1991. Metabolic implications of body fat distribution. Diabetes Care. 14:1132-1143.

3. Peiris, A., M. Sothman, R. Hoffman, and M. Hennes. 1989. Adiposity, fat distribution, and cardiovascular risk. Ann. Intern. Med. 110:867-872.

4. Kissebah, A., N. Vydelingum, R. Murray, D. Evans, A. Hartz, R. Kalkhoff, and P. Adams. 1982. Relation of body fat distribution to metabolic complications of obesity. J. Clin. Endocrinol. \& Metab. 54:254-260.

5. Després, J.-P. 1991. Obesity and lipid metabolism: relevance of body fat distribution. Curr. Opin. Lipidol. 2:5-15.

6. Randle, P. J., A. L. Kerbey, and J. Espinal. 1988. Mechanisms decreasing glucose oxidation in diabetes and starvation: role of lipid fuels and hormones. Diabetes Metab. Rev. 4:623-638.
7. Jensen, M., M. Haymond, R. Rizza, P. Cryer, and J. Miles. 1989. Influence of body fat distribution on free fatty acid metabolism in obesity. J. Clin. Invest. 83:1168-1173.

8. Felber, J.-P., E. Ferrannini, A. Golay, H. Meyer, D. Theibauld, B. Curchod, E. Maeder, E. Jequier, and R. DeFronzo. 1987. Role of lipid oxidation in pathogenesis of insulin resistance of obesity and type II diabetes. Diabetes. 36:1341-1350.

9. Lillioja, S., C. Bogardus, D. Mott, A. Kennedy, W. Knowler, and B. Howard. 1985. Relationship between insulin-stimulated glucose disposal and lipid metabolism in man. J. Clin. Invest. 75:1106-1115.

10. Zurlo, F., S. Lillioja, A. Esposito-DelPuente, B. L. Nyomba, I. Raz, M. F. Saad, B. A. Swinburn, W. C. Knowler, C. Bogardus, and E. Ravussin. 1990. Low ratio of fat to carbohydrate oxidation as predictor of weight gain: a study of 24 h RQ. Am. J. Physiol. 259(Endocrinol. Metabol. 22):E650-E657.

11. Tremblay, A. 1992. Human obesity: a defect in lipid oxidation or in thermogenesis? Int. J. Obes. 16:953-957.

12. Ferraro, R. T., R. H. Eckel, E. D. Larson, A.-M. Fontvieille, R. Rising, D. R. Jensen, and E. Ravussin. 1993. Relationship between skeletal muscle lipoprotein lipase activity and 24-hour macronutrient oxidation. J. Clin. Invest. 92:441-445

13. Richelsen, B., S. Pedersen, T. Moller-Pedersen, O. Schmitz, N. Moller and J. Borglum. 1993. Lipoprotein lipase activity in muscle tissue influenced by fatness, fat distribution and insulin in obese females. Eur. J. Clin. Invest. 23:226233.

14. Baltzan, M. A., R. Andres, G. Cader, and K. L. Zierler. 1962. Heterogeneity of forearm metabolism with special reference to free fatty acids. J. Clin. Invest. 41:116-125.

15. Dagenais, G. R., R. G. Tancredi, and K. L. Zierler. 1976. Free fatty acid oxidation by forearm muscle at rest, and evidence for an intramuscular lipid pool in the human forearm. J. Clin. Invest. 58:421-431.

16. Callaway, C., W. Chumlea, C. Bouchard, J. Himes, T. Lohman, A. Martin C. Mitchell, W. Mueller, A. Roche, and V. Seefeldt. 1988. Circumferences. In Anthropometric Standardization Reference Manual. T. G. Lohman, A. F. Roche and R. Martorel, editors. Human Kinetics, Champaign, IL. 39-54.

17. Ferland, M., J.-P. Despres, A. Tremblay, S. Pinault, A. Nadeau, S. Moorjani, P. Lupien, G. Theriault, and C. Bouchard. 1989. Assessment of adipose tissue distribution by computed axial tomography in obese women: association with body density and anthropometric measurements. Br. J. Nutr. 61:139-148.

18. Kelley, D., S. Slasky, and J. Janosky. 1991. Skeletal muscle density: effects of obesity and type II diabetes mellitus. Am. J. Clin. Nutr. 54:509-515.

19. Simoneau, J. A., S. R. Colberg, F. L. Thaete, and D. E. Kelley. 1995. Skeletal muscle glycolytic and oxidative enzyme capacities are determinants of insulin sensitivity and muscle composition in obese women. FASEB (Fed. Am. Soc. Exp. Biol.) J. 9:273-278.

20. Kelley, D., J. Reilly, T. Veneman, and L. Mandarino. 1990. The influence of physiologic hyperinsulinemia on skeletal muscle glucose storage, oxidation and glycolysis in man. Am. J. Physiol. 258:E923-E929.

21. Evans, W., S. Phinney, and V. Young. 1982. Suction applied to a muscle biopsy maximizes sample size. Med. Sci. Sports Exer. 14:101-102.

22. DeFronzo, R., J. Tobin, and R. Andres. 1979. Glucose clamp technique a method for quantifying insulin secretion and resistance. Am. J. Physiol. 237( Endocrinol. Metab. Gastrointest. Physiol. 6): E214-E223.

23. Finegood, D., R. Bergman, and M. Vranic. 1988. Modeling error and apparent isotope discrimination confound estimation of endogenous glucose production during euglycemic glucose clamps. Diabetes. 37:1025-1034.

24. Douglas, A., N. Jones, and J. Reed. 1988. Calculation of whole blood $\mathrm{CO}_{2}$ content. J. Appl. Physiol. 65:473-477.

25. Dole, V., and H. Meinertz. 1960. Microdetermination of long-chain fatty acids in plasma and tissues. J. Biol. Chem. 235:2595-2599.

26. Robin, A., J. Nordenstrom, J. Askanzi, Y. Carpentier, D. Elwyn, and J. Kinney. 1984. Influence of parenteral carbohydrate on fat oxidation in surgical patients. Surgery (St. Louis). 95:608-618.

27. Kelley, D., R. Wing, C. Buonocore, M. Fitzsimmons, J. Sturis, and K. Polonsky. 1993. Relative effects of calorie restriction and weight loss in NIDDM. J. Clin. Endocrinol. \& Metab. 77:1287-1293.

28. Gauthier, J. M., R. Thériault, G. Thériault, Y. Gélinas, and J.-A. Simoneau. 1992. Electrical stimulation-induced changes in skeletal muscle enzymes of men and women. Med. Sci. Sports Exerc. 24:1252-1256.

29. Zammit, V. A., and E. A. Newsholme. 1979. Activation of enzymes of fat and ketone body metabolism and effects of starvation on blood concentrations of glucose and fat fuels in teleost and elasmobranch fish. Biochem. J. 184:312322.

30. Bass, A., D. Brudiczk, P. Eyer, S. Hofer, and D. Pette. 1969. Metabolic differentiation of distinct muscle types at the level of enzymatic organization. Eur. J. Biochem. 10:198-206.

31. Kelley, D., M. Mokan, J.-A. Simoneau, and L. Mandarino. 1993. Interaction between glucose and free fatty acid metabolism in human skeletal muscle J. Clin. Invest. 92:91-98. 
32. Frayn, K. 1983. Calculation of substrate oxidation rates in vivo from gaseous exchange. J. Appl. Physiol. 55:628-633.

33. Gefland, R., and E. Barrett. 1987. Effect of physiologic hyperinsulinemia on skeletal muscle protein synthesis and breakdown in man. J. Clin. Invest. 80:16.

34. Martin, M., and M. Jensen. 1991. Effects of body fat distribution on regional lipolysis in obesity. J. Clin. Invest. 88:609-613.

35. Boden, G., F. Jadall, J. White, Y. Liang, M. Mozzoli, X. Chen, E. Coleman, and C. Smith. 1991. Effects of fat on insulin stimulated carbohydrate metabolism in normal men. J. Clin. Invest. 88:960-966.

36. Newsholme, E., and A. Leech. 1983. Chapter 4. The oxidation of acetyl coenzyme-A. In Biochemistry for the Medical Sciences. John Wiley and Sons Ltd., Chichester, United Kingdom.

37. Shumate, J., J. Carroll, M. Brooke, and R. Choski. 1982. Palmitate oxidation in human muscle: comparison to CPT and carnitine. Muscle \& Nerve. 5:226231.

38. Howald, H., D. Pette, J.-A. Simoneau, A. Uber, H. Hoppeler, and P. Corretelli. 1990. Effects of chronic hypoxia on muscle enzyme activities. Int. $J$. Sports Med. 11 (Suppl. 1):S10-S14.

39. Kiens, B., H. Lithell, K. J. Mikines, and E. Richter. 1989. Effects of insulin and exercise on muscle lipoprotein lipase activity in man and its relation to insulin action. J. Clin. Invest. 84:1124-1129.

40. Turcotte, L. P., E. Richter, and B. Kiens. 1992. Increased plasma FFA uptake and oxidation during prolonged exercise in trained vs. untrained humans. Am. J. Physiol. 262 (Endocrinol. Metab. 25):E791-E799.

41. Kelley, D., and J.-A. Simoneau. 1994. Impaired free fatty acid utilization by skeletal muscle in non-insulin-dependent diabetes mellitus. J. Clin. Invest. 94:2349-2356.

42. Mandarino, L. J., A. Consoli, A. Jain, and D. Kelley. 1993. Differential regulation of intracellular glucose metabolism by glucose and insulin in human muscle. Am. J. Physiol. 265 (Endocrinol. Metab. 28):E898-E905.

43. Campbell, P. J., M. G. Carison, and N. Nurjahan. 1994. Fat metabolism in human obesity. Am. J. Physiol. 266 (Endocrinol. Metab. 29):E600-E605

44. Storlien, L., A. Jenkins, D. Chisholm, W. Pascoe, S. Khouri, and E. Kraegen. 1991. Influence of dietary fat composition on development of insulin resistance in rats: relationship to muscle triglyceride and $w 3$ fatty acids in muscle phospholipid. Diabetes. 40:280-289.

45. Evans, D., R. Hoffman, R. Kalkhoff, and A. Kissebah. 1984. Relationship of body fat topography to insulin sensitivity and metabolic profiles in premenopausal women. Metab. Clin. Exp. 33:68-75.

46. Carlson, M. G., W. L. Snead, J. O. Hill, N. Nurjhan, and P. J. Campbell. 1991. Glucose regulation of lipid metabolism in humans. Am. J. Physiol. 261 (Endocrinol. Metab. 24):E815-E820.

47. Rossetti, L., and M. Hu. 1993. Skeletal muscle glycogenolysis is more sensitive to insulin than is glucose transport/phosphorylation. J. Clin. Invest. 92:2963-2974. 